\title{
Complete Blood Count Profile and Derived Inflammatory Markers in Children with Severe Acute Malnutrition Seen in Sokoto, North-Western Nigeria
}

\author{
K. O. Isezuo, U. M. Sani, U. M. Waziri, B. I. Garba, M. Amodu-Sanni, \\ A. Adamu, F. B. Jiya, and T. Yusuf
}

\section{ABSTRACT}

Severe acute malnutrition (SAM) is a major cause of mortality among children in Nigeria. Majority of affected children die from sepsis related complications. The complete blood count includes inflammatory markers which have been found to be useful in predicting sepsis and mortality in children, but these findings have not been corroborated in our population. The aim of this study was to compare the haematological profile and inflammatory markers of severely malnourished children to age matched controls admitted for febrile illnesses. It was a cross sectional study carried out in the emergency paediatric unit of Usmanu Danfodiyo University Teaching Hospital, Sokoto. Severely malnourished children aged 6 months to 5 years and a comparative cohort who were not severely malnourished were consecutively recruited as they presented for admission. Relevant data were entered into a proforma and blood samples taken for complete blood count amongst others. Total and differential white cell counts, lymphocyteneutrophil ratio and platelet indices were compared. There were 64 children comprising 32 severely malnourished and 32 well-nourished children. Mean white cell count, absolute lymphocyte and monocytes were significantly higher among the malnourished while mean platelet volume (MPV) and platelet distribution width (PDW) were significantly lower for the malnourished subjects. There were eight mortalities all among the malnourished children and mean neutrophil count was significantly higher among the mortalities. In conclusion, severely malnourished children had more lymphocytosis, however, mortality was associated with neutrophilia. Platelet indices of inflammation were lower in malnourished than nonmalnourished subjects.

Keywords: SAM, FBC, MPV, NLR, PDW, sepsis, mortality.

Published Online: February 7, 2021

ISSN: $2593-8339$

DOI: 10.24018 / ejmed.2021.3.1.662

\section{K. O. Isezuo*}

Department of Paediatrics, UDUTH, Nigeria.

(e-mail: khadisez ${ }^{@}$ yahoo.com)

U. M. Sani

(e-mail: usmansani2005@gmail.com)

\section{U.M Waziri}

(e-mail: wazirium ${ }^{\circledR}$ gmail.com)

B. I. Garba

(e-mail: bgilah@gmail.com)

M. Amodu-Sanni

(e-mail: maryamamodusanni ${ }^{@ g m a i l . c o m) ~}$

A. Adamu

(e-mail: nanadamu ${ }^{\circledR}$ gmail.com)

F. B. Jiya

(e-mail: fatimabellojiya ${ }^{@}$ gmail.com)

T. Yusuf

(e-mail: dimeji74@gmail.com)

*Corresponding Author

\section{INTRODUCTION}

Severe acute malnutrition (SAM) is a major cause of mortality among children aged under five years in Nigeria. It contributes to about $50 \%$ of under-five mortality with a mortality rate ranging from $10 \%$ to $40 \%$ in hospitalized cases [1]. Overwhelming infection to which they lack ability to mount adequate immune response is a major cause of mortality in them [2]. Due to paucity of microbiological investigations in this setting and their high susceptibility to bacterial infection, they are placed on empirical broad spectrum antibiotic therapy pending results which may not be available in many instances. The complete blood count is a relatively available and affordable test which is routine and practical. It provides information about a patients' blood components [3].

White blood cells which include lymphocytes and neutrophils are the major cells deployed by the immune system during an infective process. The predominant type of white cell depends on the cause, stage of infection and immunity of the patient which is affected also by the nutritional status [3].
Aside from the white cell counts, differential count, red cell indices and platelet counts, some inflammatory markers derived from the complete blood count have been found to be useful in predicting sepsis and also prognostication in both children and adults with various infective and inflammatory conditions such as bacterial and viral infections like pneumonia, atopic disorders, asthma, appendicitis and other gastrointestinal disorders [4], [5]. These include neutrophil to lymphocyte ratio (NLR), mean platelet volume (MPV), platelet distribution width (PDW) and other ratios between these markers [6]-[8].

Neutrophil lymphocyte ratio is an indicator of systemic inflammation even when white cell count is within the normal range. It is predictive in the prognosis of both acute and chronic inflammatory processes [7]. Platelets, when activated during an infective process, increase in size leading to increase in the MPV. They are also altered in size affecting the platelet distribution width and are metabolically active, producing chemokines and cytokines which mediate in the inflammatory process [8].

These findings have not been corroborated in our population despite being a high burden country of childhood 
infectious diseases and a home to $10 \%$ of the severely malnourished children worldwide [9].

This study was therefore carried out to compare the haematological profile and inflammatory markers of severely malnourished children to non-malnourished controls admitted for febrile illnesses with an aim to ascertain whether the inflammatory markers that predict sepsis are predominant in severely malnourished patients and their effect on morbidity and mortality.

\section{MethodOLOGY}

\section{A. Study Area}

The study was carried out at the Emergency Paediatric Unit of Usmanu Danfodiyo University Teaching Hospital (UDUTH), Sokoto which is a tertiary health facility located in the Sokoto State capital. This hospital serves as a referral centre for inhabitants of the States of Sokoto, Zamfara, Kebbi; and some neighbouring countries in the West African sub-region. The hospital has different specialties in the various departments.

Sokoto town lies between latitude $10^{\circ}$ and $14^{\circ} \mathrm{N}$, and longitude $3^{\circ} 3^{1}$ and $7^{\circ} 7^{1}$ east of the Equator and is located in the dry Sahel region and is surrounded by sandy Savannah. ${ }^{10}$ The rainy season is short and begins late in May till September with a mean annual rainfall of $550 \mathrm{~mm}$. The dry season is longer and comprises the hot dry season from March to April and the cold dry season from November to February [10], [11]. The inhabitants are mainly agrarian in nature and cases of malnutrition in children usually peak during the early rainy when dry grain stocks run out and parents are involved in intense planting activities [12].

\section{B. Study Design}

It was a cross-sectional study carried out among patients admitted into the emergency unit from $1^{\text {st }}$ May 2019 to $31^{\text {st }}$ December 2019.

\section{Sample Size Determination}

The minimum sample size was determined with the formula [13]:

$$
\mathrm{n}=\left(\mathrm{Z}^{2} \times \alpha^{2}\right) / \mathrm{d}^{2}
$$

$\alpha=$ standard deviation of white cell count from a previous study in Sudan $[14]=5.2$ cells $/ \mu \mathrm{L}$ with a precision margin of 2.5 cells $/ \mu \mathrm{L}=16$ subjects. Therefore, 32 subjects with severe malnutrition and 32 subjects without malnutrition were consecutively enrolled as they were admitted into the study.

\section{Inclusion and exclusion criteria}

For SAM: Patients admitted with weight for length/height of $<-3 \mathrm{SD}$, mid arm circumference of $<11$ centimeters, or symmetrical oedema aged 6 months to 5 years with poor nutritional history were enrolled.

For non-SAM: Patients aged 6 months to 5 years admitted with fever and other acute symptoms of 3 days or less with normal nutritional status (weight for length/height of > -1SD) whose caregivers consented were enrolled consecutively.

Exclusion criteria: Those who had been admitted or had antibiotics within previous 2 weeks, those with severe malaria, those with altered consciousness, diagnosis of measles, tuberculosis and retroviral infection were excluded.

\section{E. Instruments of data collection}

A standardized proforma was utilized to collect demographic data, presenting symptoms, weight, height, mid-arm circumference and duration of admission. The laboratory results as obtained were entered.

\section{F. Materials/ equipment of data collection}

Ethylene diamine tetra-acetic acid (EDTA) bottles, $2 \mathrm{ml}$ and $5 \mathrm{ml}$ syringes, Disposable gloves, Table top electronic weighing scale/ Wunder beam balance table top weighing scale, non-stretch tape measure, Automated haem analyzer in the haematology laboratory.

\section{G. Subject handling procedure}

They were enrolled as they presented consecutively to the emergency unit. After being stabilized and reviewed by admitting officer, the required anthropometric examination was used to categorise them into the 2 groups of SAM. Caregivers then gave more information and consent for the study. Those who consented had blood samples taken via sterile procedure into an EDTA bottle. This was analysed via standard procedure using the automated Haem analyser in the Haematology Department.

\section{H. Parameters Assessed}

1. Total white blood cell count (WBC).

2. Lymphocyte count percentage (LCP).

3. Lymphocyte count (LYM).

4. Neutrophil count percentage (NCP).

5. Absolute Neutrophil count (ANC).

6. Monocytes, Basophils, Eosinophils count (MXD).

7. Platelet count (PLT).

8. Haematocrit (HCT).

9. Mean Corpuscular Volume, Haemoglobin and Haemoglobin concentration (MCV, MCH, MCHC).

10. Neutrophil lymphocyte ratio (NLR): Ratio of the absolute neutrophil and lymphocyte count.

11. Mean platelet volume (MPV).

12. Plateletcrit (PCT).

13. Platelet distribution width (PDW).

14. MPV/PLT.

15. MPV X PDW/ PLT X PCT.

\section{Data Analysis}

Data was analyzed using Statistical Package for Social Science (SPSS) statistical software (version 22.0). Chi square test was used to determine associations between categorical variables and Fischer's exact test was used when an expected cell value is less than 5 . Student t-test was used to assess the mean differences. The level of statistical significance was set at $\mathrm{p}$ - value $<0.05$.

\section{J. Ethical considerations}

Ethical approval for the study was obtained from the Ethics Committee of Usmanu Danfodiyo University Teaching Hospital Sokoto. 


\section{Results}

\section{A. Sociodemographic Profile}

There were 64 patients in all comprising 32 SAM patients and 32 non-SAM patients. There was a female preponderance of 40 females $(62.5 \%)$ and 24 males $(37.5 \%)$ males. Both groups had equal number according to gender $\left(X^{2}=0.00\right.$; $\mathrm{p}=1.0)$. The mean age of both groups was also similar 33.5 (15.6) months vs 24.8 (14.0) months, $(\mathrm{t}=0.13, \mathrm{p}=0.42)$ with an age range of 6 to 60 months. All $(100 \%)$ of the SAM patients were of low socioeconomic status whereas 19 $(59.4 \%)$ of the non-SAM group were of low social status. (Table I). The diagnosis in the comparison group included acute pharyngitis, acute diarrhoeal disease and pneumonia.

TABLE I: SOCIO-DEMOGRAPHIC AND CLINICAL CHARACTERISTICS

\begin{tabular}{ccccc}
\hline \hline Parameter & $\begin{array}{c}\text { SAM } \\
\mathrm{n}=32(\%)\end{array}$ & $\begin{array}{c}\text { Non-SAM } \\
\mathrm{n}=32(\%)\end{array}$ & $\begin{array}{c}\text { Test } \\
\text { statistic }\end{array}$ & p-value \\
\hline Mean age & $24.8(14.0)$ & $33.5(15.6)$ & $\mathrm{t}-0.13$ & 0.42 \\
Gender & $12(37.5)$ & $12(37.5)$ & $\mathrm{X}^{2}=$ & 1.0 \\
Male & $20(62.5)$ & $20(62.5)$ & 0.00 & \\
Female & & & & \\
Socio-economic & & & & \\
status & $0(0.0)$ & $0(0.0)$ & & \\
Upper & $0(0.0)$ & $13(62.5)$ & & \\
Middle & $32(100)$ & $19(59.4)$ & & \\
Lower & & &
\end{tabular}

Type of SAM

Non-oedematous $26(81.3)$

Oedematous $6(18.7)$

\section{B. Haematological Profile of SAM patients Compared to} Non-SAM

In the table below are details of the haematological profile of the malnourished as compared to those without SAM. The total WBC, absolute lymphocyte, monocyte count and lymphocyte count percentage (LCP) were higher in the SAM group while neutrophil count percentage (NCP) and mean corpuscular volume (MCV) were significantly higher in the non-SAM group. (see Table II).

\begin{tabular}{|c|c|c|c|c|}
\hline Parameter & $\begin{array}{c}\text { SAM } \\
\mathrm{n}=32 \\
(\mathrm{mean} \pm \mathrm{sd})\end{array}$ & $\begin{array}{c}\text { Non-SAM } \\
n=32 \\
(\text { mean } \pm \text { sd })\end{array}$ & $\begin{array}{c}\text { Test } \\
\text { statistic } \\
\text { (t-test) }\end{array}$ & p-value \\
\hline WBC $($ cells $/ \mu \mathrm{L})$ & $14.3 \pm 7.4$ & $8.8 \pm 2.8$ & -0.386 & 0.001* \\
\hline $\operatorname{LCP}(\%)$ & $46.1 \pm 19.4$ & $38.6 \pm 13.5$ & -1.72 & 0.090 \\
\hline LYM (cells/ $\mu \mathrm{L})$ & $6247 \pm 3693$ & $3437 \pm 1676$ & -3.70 & $0.001 *$ \\
\hline $\mathrm{NCP}(\%)$ & $39.7 \pm 20.4$ & $52.6 \pm 13.6$ & 2.80 & 0.006* \\
\hline ANC (cells/ $\mu \mathrm{L})$ & $5922 \pm 4639$ & $4848 \pm 2179$ & -1.1 & 0.260 \\
\hline $\operatorname{MXD}(\%)$ & $11.0 \pm 6.1$ & $8.8 \pm 3.7$ & -1.5 & 0.120 \\
\hline MXD (cells $/ \mu \mathrm{L}$ & $1562 \pm 1301$ & $754 \pm 278$ & -3.31 & $0.002 *$ \\
\hline PLT (cells/ $\mu \mathrm{L})$ & $366 \pm 161$ & $344 \pm 164$ & -0.81 & 0.420 \\
\hline $\mathrm{HCT}(\%)$ & $33.2 \pm 15.8$ & $33.6 \pm 5.8$ & 0.13 & 0.900 \\
\hline $\operatorname{MCV}(\mathrm{fl})$ & $71.9 \pm 6.7$ & $75.9 \pm 4.8$ & 2.64 & 0.011* \\
\hline $\mathrm{MCH}(\mathrm{pg})$ & $24.5 \pm 3.4$ & $24.5 \pm 2.3$ & -5.1 & 0.600 \\
\hline $\operatorname{MCHC}(\mathrm{g})$ & $35.6 \pm 11.5$ & $31.8 \pm 1.6$ & -1.85 & 0.070 \\
\hline
\end{tabular}

\section{Inflammatory Markers of SAM Patients Compared to Non-SAM Patients}

The table below shows the comparative analysis of the inflammatory markers and ratios derived from the full blood count compared to those without SAM. Most of the platelet parameters were higher among the non-SAM group, however the difference was only significant for the MPV and PDW. The NLR was also higher among the non-SAM but not significant.

TABLE III: COMPARISON OF INFLAMMATORY MARKERS IN SAM AND NON-SAM CASES

\begin{tabular}{|c|c|c|c|c|}
\hline Parameter & $\begin{array}{c}\text { SAM } \\
\mathrm{n}=32 \\
(\mathrm{mean} \pm \mathrm{sd})\end{array}$ & $\begin{array}{c}\text { Non-SAM } \\
\mathrm{n}=32 \\
(\mathrm{mean} \pm \mathrm{sd})\end{array}$ & $\begin{array}{c}\text { Test } \\
\text { statistic } \\
\text { (t-test) }\end{array}$ & $\mathrm{p}$-value \\
\hline NLR & $1.44 \pm 2.18$ & $1.71 \pm 1.12$ & -0.6 & 0.600 \\
\hline $\operatorname{MPV}(\%)$ & $8.2 \pm 2.8$ & $9.3 \pm 0.8$ & 2.14 & $0.04 *$ \\
\hline PCT (cells/ $\mu \mathrm{L})$ & $0.34 \pm 0.24$ & $0.31 \pm 0.15$ & -0.63 & 0.55 \\
\hline PDW (\%) & $13.6 \pm 1.7$ & $15.0 \pm 1.5$ & 3.50 & $0.01 *$ \\
\hline MPV/PLT & $0.03 \pm 0.01$ & $0.05 \pm 0.05$ & 2.0 & 0.05 \\
\hline $\begin{array}{c}\text { MPVPDWPLTPC } \\
\mathrm{T}\end{array}$ & $0.1 \pm 0.07$ & $0.13 \pm 0.03$ & 1.95 & 0.06 \\
\hline
\end{tabular}

\section{Comparison of Parameters of Survivors and Non- Survivors among the SAM Patients}

Eight $(25 \%)$ of the SAM patients died. The following table below shows the comparative analysis of the inflammatory markers and ratios of the survivors and non survivors among the SAM patients. The only significant difference was seen in the absolute neutrophil count and neutrophil count percentage. The NLR was also higher in the non-survivors but not significant.

TABLE IV: COMPARISON OF PARAMETERS OF SURVIVORS AND NONSURVIVORS AMONG THE SAM CASES

\begin{tabular}{ccccc}
\multicolumn{5}{c}{ SURVIVORS AMONG THE SAM CASES } \\
\hline Parameter & $\begin{array}{c}\text { Survivors } \\
\mathrm{n}=24 \\
(\mathrm{mean} \pm \mathrm{sd})\end{array}$ & $\begin{array}{c}\text { Non- } \\
\text { Survivors } \\
\mathrm{n}=8 \\
(\mathrm{mean} \pm \mathrm{sd})\end{array}$ & $\begin{array}{c}\text { Test } \\
\text { statistic } \\
(\mathrm{t} \text {-test })\end{array}$ & p-value \\
\hline WBC (cells $/ \mu \mathrm{L})$ & $12.1 \pm 5.3$ & $18.6 \pm 11.4$ & -1.97 & 0.06 \\
LCP $(\%)$ & $50.5 \pm 18.4$ & $36.1 \pm 22.2$ & 1.6 & 0.10 \\
LYM (cells $/ \mu \mathrm{L})$ & $6007 \pm 3529$ & $6443 \pm 4834$ & -0.250 & 0.80 \\
NCP $(\%)$ & $33.0 \pm 17.8$ & $52.8 \pm 23.8$ & -2.2 & $\mathbf{0 . 0 4}$ \\
ANC (cells $/ \mu \mathrm{L})$ & $4049 \pm 2536$ & $9981 \pm 7118$ & -3.0 & $\mathbf{0 . 0 0 5}$ \\
MXD $(\%)$ & $12.0 \pm 6.7$ & $9.5 \pm 3.5$ & 1.7 & 0.40 \\
MXD (cells $/ \mu \mathrm{L}$ & $1536 \pm 1271$ & $1899 \pm 1713$ & -0.5 & 0.6 \\
PLT (cells $/ \mu \mathrm{L})$ & $351 \pm 158$ & $374 \pm 152$ & -3.3 & 0.74 \\
NLR & $0.94 \pm 0.90$ & $2.99 \pm 4.3$ & -1.9 & $\mathbf{0 . 0 5}$ \\
HCT $(\%)$ & $36.3 \pm 18.9$ & $27.0 \pm 6.9$ & 1.81 & 0.08 \\
MPV $(\mathrm{fl})$ & $8.1 \pm 3.4$ & $8.3 \pm 0.7$ & -0.15 & 0.87 \\
\hline
\end{tabular}

\section{E. Correlation with Duration of Admission}

Only the NLR had a significant correlation with the duration of admission among the parameters in the SAM survivors which was a moderate positive correlation $(\mathrm{r}=0.502, \mathrm{p}=0.034)$ implying that the higher the neutrophil count, the longer was the admission duration.

\section{DISCUSSION}

This study compared haematological parameters and inflammatory markers in the complete blood count of severely malnourished patients with other febrile patients who were not malnourished. Most of the patients affected with malnutrition were female, a finding seen in some other studies [15], [16] of female preponderance which has been attributed to more care for the male child. Most of the patients were of lower social economic strata which is not unexpected as it corroborates previous findings [15], [16].

The WBC count was elevated than in the comparison group 
similar to a comparative study by Bashier [14] in Sudan which showed marked leucocytosis in the SAM group. However, the differential counts were more of lymphocytes and other white cells while the neutrophils percentage was lower in the malnourished group. This lymphocyte predominance in malnourished under-fives is similar to what more studies reported as shown in a systematic review by Rytter [17] where it was shown that fewer studies showed neutrophil predominance. This is despite the reported lymphoid organs atrophy which occurs in malnutrition [17]. Given the long duration of exposure of malnourished patients to infectious pathogens, this may not be unexpected when compared to the other group with good nutritional status who had predominance of neutrophils. Similar findings for the mixed cells (monocytes, basophils and eosinophils) reported showed predominance in the SAM group as was also noted by the authors of the systematic review [17].

Haematocrit levels were similar in the SAM and non-SAM group which was an unusual finding as anaemia of severe form is expected in SAM as one of the acute complications [18]. Bashier [14] and others [17] reported significant difference in the HCT of their subjects when compared to those with malnutrition. A possible reason for the apparent absence of anaemia in the SAM group at presentation may be due to haemoconcentration from dehydration as the blood sample was taken at presentation before dehydration was fully corrected to reflect "true" haematocrit levels. However, similar to other reports, MCV which is reflective of the iron status of the patients was lower in the SAM group. Similar value was reported by Ernest from south east Nigeria and Bashier from Sudan [15], [19]. Worldwide, iron deficiency is the most common trace element deficiency affecting up to $50 \%$ of the world's population and it is worse in the severely malnourished [18].

For the derived markers of inflammation, the MPV and PDW were higher in the non-SAM group likewise the NLR and MPV/PLT ratio but the latter 2 did not attain statistical significance. The NLR has been shown to be a useful parameter in predicting bacteremia in emergency settings initially in adult studies [20] and cutoffs later evaluated for children [21]. NLR as well as other derived markers are lowcost and easily obtainable parameters that do not require any special equipment apart from routine automated complete blood count machine [20]. NLR was higher amongst the nonSAM unlike the SAM group, while this does not preclude bacterial sepsis in the SAM group, it is worth noting that nonsurvivors among the SAM patients had higher NLR of 2.99 probably supporting severe infection. The non-survivors also had higher neutrophil counts and absolute values corroborating this. Bekdas [22] in a study in children with pneumonia showed that a ratio of 1.7 and above predicted bacterial pneumonia while Dursun [21] got a value of $>1.97$ supported sepsis at $75.6 \%$ sensitivity and $38.4 \%$ specificity. The NLR in this study was the only index that had a positive correlation with duration of admission among the SAM survivors.

The increase in mean platelet volume has also been found to be useful in predicting bacterial sepsis as activated platelets increase in size and produce a lot of inflammatory mediators. Values ranging between 8.2 and $8.5 \mathrm{fl}$ have been observed as predictable of sepsis with higher values in neonates [21], [23] in this study, the non-SAM had significantly higher MPV value of $9.3 \mathrm{fl}$ probably suggesting more active immune reaction to bacterial infection than the SAM group. The nonsurvivors among the SAM group also had higher MPV $(8.3 \mathrm{fl})$ but not significant suggesting more severe infection.

Platelet activation causes changes of platelets, including both spherical shape and pseudopodia formation. Platelets with increased number and size of pseudopodia differ in size, which affects PDW which increases in sepsis [24]. Sayed [25] in a study on admission platelet indices showed PDW was higher in non-survivors of sepsis but not significant, rather plateletcrit (PCT) and MPV/PCT ratio were significantly associated with mortality. Similar findings were also reported by Golwala [26]. In this study, the values of PDW, MPV/PCT were higher among the non-survivors of SAM but did not attain statistical significance.

\section{CONCLUSION}

Severely malnourished children in this study had more lymphocytosis however, mortality was associated with neutrophilia. Platelet indices of inflammation and sepsis were lower in the severely malnourished group than nonmalnourished subjects, however, among the malnourished group, the indices were higher among the non-survivors. NLR, MPV and PDW may be an early useful index to predict mortality in SAM patients.

\section{ACKNOWLEDGMENT}

We acknowledge all the caregivers and their wards who for their patience and participation.

\section{REFERENCES}

[1] Gachau S, Irimu G, Ayieko P, Akech S, Agweyu A, et al. Prevalence, outcome and quality of care among children hospitalized with severe acute malnutrition in Kenyan hospitals: A multi-site observational study. PLOS ONE 2018; 13: e0197607.

[2] Rytter MJH, Kolte L, Briend A, Friis H, Christensen VB. The Immune System in Children with Malnutrition. A Systematic Review. PLOS ONE 2014; 9 (8): e105017. https://doi.org/10.1371/journal.pone.0105017.

[3] Ted Gordon-Smith,Structure and function of red and white blood cells, Medicine,Volume 41, Issue 4,2013,Pages193-199,ISSN $1357-$ 3039,https://doi.org/10.1016/j.mpmed.2013.01.023.

[4] Tamelytė E, Vaičekauskienė G, Dagys A, Lapinskas T, Jankauskaitė L. Early Blood Biomarkers to Improve Sepsis/Bacteremia Diagnostics in Pediatric Emergency Settings. Medicinia (Kaunas) 2019; 55 (4): 99.

[5] Karadag-Oncel E, Ozsurekci Y, Kara A, Karahan S, Cengiz AB, Ceyhan M. The value of mean platelet volume in the determination of community acquired pneumonia in children. Italian Journal of Pediatrics 2013; 39:16. https://doi.org/10.1186/1824-7288-39-16.

[6] Orak M, Karakoç Y, Ustundag M, Yildirim Y, Celen MK, Güloglu C. An investigation of the effects of the mean platelet volume, platelet distribution width, platelet/lymphocyte ratio, and platelet counts on mortality in patents with sepsis who applied to the emergency department. Niger J Clin Pract. 2018;21(5):667-671. doi: 10.4103/njcp.njcp_44_17. PMID: 29735870.

[7] Araújo FDDR, Silva RMFDL, Oliveira CAL, Meira ZMA. Neutrophilto-lymphocyte ratio used as prognostic factor marker for dilated cardiomyopathy in childhood and adolescence. Ann Pediatr Cardiol. 2019;12(1):18-24. doi: 10.4103/apc.APC_47_18. PMID: 30745765; PMCID: PMC6343383.

[8] Golwala ZM, Shah H, Gupta N, Sreenivas V, Puliyel JM. Mean Platelet Volume (MPV), Platelet Distribution Width (PDW), Platelet Count and Plateletcrit (PCT) as predictors of in-hospital paediatric mortality: a 
case-control Study. Afr Health Sci. 2016;16(2):356-62. doi: 10.4314/ahs.v16i2.3. PMID: 27605950; PMCID: PMC4994558.

[9] Severe Acute Malnutrition Management in Nigeria. (2019) Challenges, Lessons and the road ahead. Executive Summary March 2015. ACF International.

[10] National Population Commission. 2006 National Census: Federal Republic of Nigeria Official Gazette, 2007; 94(24):196. W.-K. Chen, Linear Networks and Systems, Belmont, CA: Wadsworth, 1993, pp. 123-135.

[11] Udo R, Mamman A. Nigeria: Giant in the tropics. State surveys, 1993:435-446

[12] Spring. 2018. Assessing Drivers of Malnutrition in Nigeria: A Report on Findings from Kebbi, Niger, Benue, and Cross River to Inform Food Security Investments. Arlington, VA: Strengthening Partnerships, Results, and Innovations in Nutrition Globally (SPRING) project. https://www.springnutrition.org/sites/default/files/publications/reports /nigeria_drivers_report_2-18_0.pdf (accessed 3/1/2021).

[13] Araoye MO. Sample size calculation in: MO Araoye. Research Methodology with Statistics for Health and Social Sciences. Nathdex (Publ) Ilorin 2004;115-121.

[14] Basheir, Haider \& Hamza, Khalda. Hematological Parameters of Malnourished Sudanese Children Under 5 Years - Khartoum State 2011. Journal of Clinical Medicine 2015; 1(4):152-156.

[15] Aliyu I, Ibrahim HU, Idris U, Michael GC, Ibrahim UA, Mohammed A, Ahmad I, Habib JM. The clinical profile and outcome of children with acute malnutrition in a tertiary health center in North-West Nigeria: A 1-year retrospective review. J Clin Sci 2020;17:120-6.

[16] Adegoke, Olufemi \& Arif, Muhammad \& Bahwere, Paluku \& Harb, Jana \& Hug, Julia \& Jasper, Paul \& Mudzongo, Paul \& Nanama, Simeon \& Olisenekwu, Gloria \& Visram, Aly. Incidence of severe acute malnutrition after treatment: A prospective matched cohort study in Sokoto, Nigeria. Maternal \& Child Nutrition 2000;17. 10.1111/mcn. 13070 .

[17] Rytter MJ, Kolte L, Briend A, Friis H, Christensen VB. The immune system in children with malnutrition--a systematic review. PLoS One. 2014;9(8):e105017. doi: 10.1371/journal.pone.0105017. PMID: 25153531; PMCID: PMC4143239.Giv.

[18] WHO 2013. Guideline: Updates on the Management of Severe Acute Malnutrition in Infants and Children. Geneva: WHO.

[19] Ernest N, Akpan P and Emmanuel UKO. Reduced Levels of Some Iron Parameters of PEM Malnourished Children. Journal of Biology, Agriculture and Health Care 2013; 3 (13): 114-120.

[20] Holub, Michal \& Beran, Ondřej \& Kaspř́íková, Nikola \& Chalupa, Pavel. Neutrophil to lymphocyte count ratio as a biomarker of bacterial infections. Central European Journal of Medicine 2012; 7. 10.2478/s11536-012-0002-3.

[21] Dursun A, Ozsoylu S, Akyildiz BN. Neutrophil-to-lymphocyte ratio and mean platelet volume can be useful markers to predict sepsis in children. Pak J Med Sci 2018;34(4):918-922. doi: 10.12669/pjms.344.14547. PMID: 30190753; PMCID: PMC6115542.

[22] Bekdas M, Goksugur SB, Sarac EG, Erkocoglu M, Demircioglu F. Neutrophil/lymphocyte and C-reactive protein/mean platelet volume ratios in differentiating between viral and bacterial pneumonias and diagnosing early complications in children. Saudi Med J. 2014;35(5):442-447.

[23] Tekin M, Konca C, Gulyuz A, Uckardes F, Turgut M. Is the mean platelet volume a predictive marker for the diagnosis of acute pyelonephritis in children? Clin Exp Nephrol. 2015;19(4):688-693. doi:10.1007/s10157-014-1049-z.

[24] Vagdatli E, Gounari E, Lazaridou E, Katsibourlia E, Tsikopoulou F, Labrianou I. Platelet distribution width: a simple, practical and specific marker of activation of coagulation. Hippokratia. 2010;14:28-32.

[25] Sayed, Samira \& Mahmoud, Mohamed \& Moness, Hend \& Mousa, Suzan. Admission platelet count and indices as predictors of outcome in children with severe Sepsis: a prospective hospital-based study. BMC Pediatrics 2020; 20. 10.1186/s12887-020-02278-4.

[26] Golwala ZM, Shah H, Gupta N, Sreenivas V, Puliyel JM. Mean Platelet Volume (MPV), Platelet Distribution Width (PDW), Platelet Count and Plateletcrit (PCT) as predictors of in-hospital paediatric mortality: a case-control Study. Afr Health Sci 2016;16(2):356-62. doi 10.4314/ahs.v16i2.3. PMID: 27605950; PMCID: PMC4994558. 